on Hospital Infection is scheduled to be held in Beijing China on October 25-27, 1994. The conference is being sponsored by the Society of Nosocomial Infection Control and the China Preventive Medical Association. Additional information on the conference can be obtained from the conference secretariat: Department of Epidemiology; Chaoyang District, Beijing, 100020, Peoples Republic of China; FAX: 8\&1-9741693.

\section{Standards for Healthcare Networks Developed by JCAHO}

Standards for accreditation of healthcare networks have been approved recently by the Joint Commission on Accreditation of Healthcare Organizations Board of Commissioners. Standards cover the performance of the network with respect to patient rights and responsibilities, organization ethics, continuum of care, education and communication, and improving network performance. Requirements relating to clinical care are referenced to the standards that apply to specific care delivery sites.

\section{Dental Infection Control Kit Available from CDC}

The Centers for Disease Control and Prevention (CDC) has issued an updated version of a kit for infection control practices in dentistry, entitled "Dental Infection Control File, 1993." The kit contains brochures on hepatitis B and HIV; a workbook for the education of the dental practice team; a copy of the CDC's Recommended Infection Control Practices for Dentistry, 1993; a wall chart illustrating the steps involved in heat sterilization; and a set of charts describing postexposure management of dental personnel exposed to blood of patients. The kit may be ordered from the National Technical Information Service for $\$ 25.00$ (document no. PB-94113990) NTIS, 5285 Port Royal Rd., Springfield, VA 22161; telephone (708) 487-4650.

The CDC also offers telephone support for dental practices interested in specific infection control information through the CDC Voice Information Service at (404) 332-4552. 